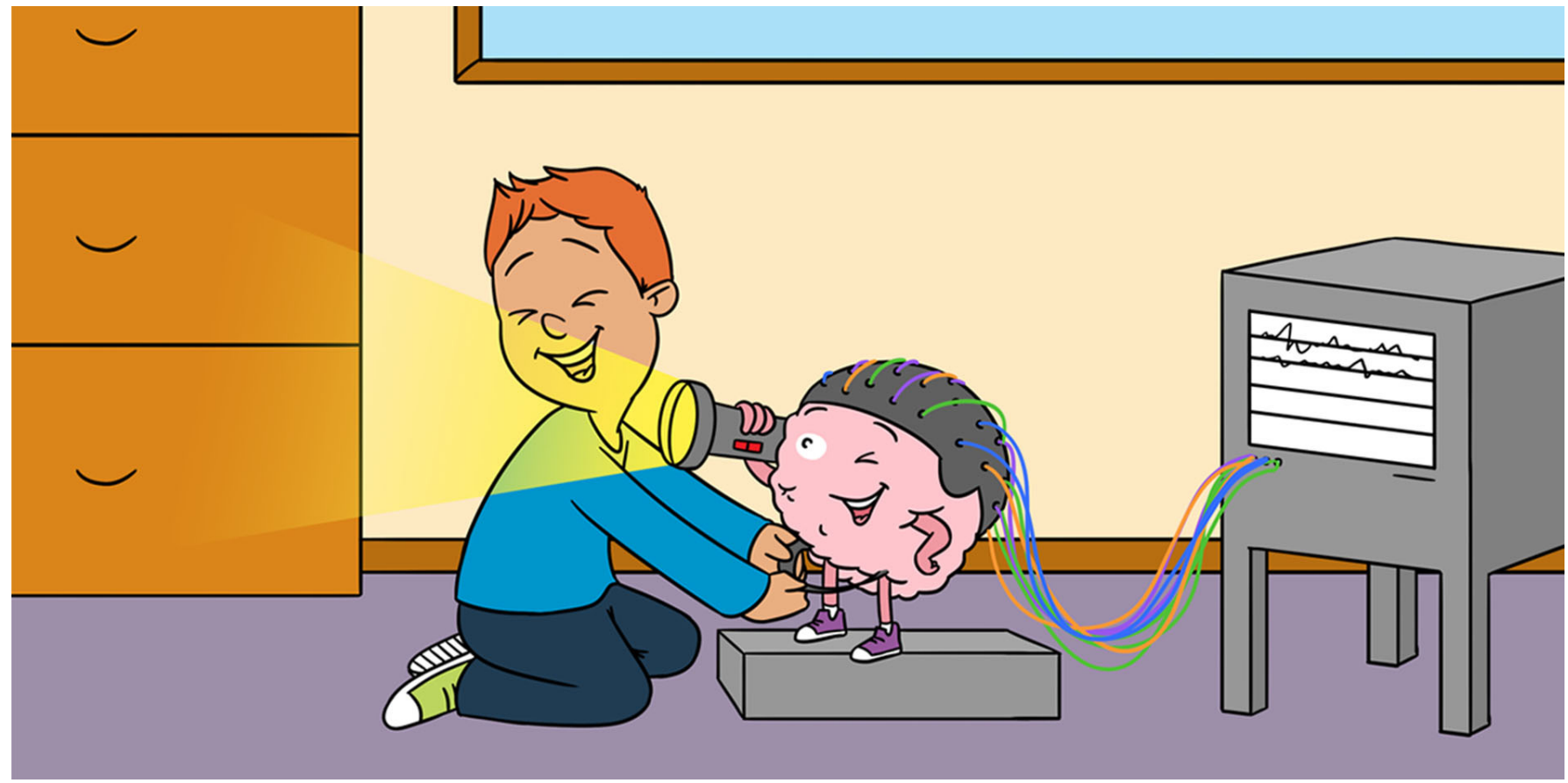

\title{
USING LIGHT TO UNDERSTAND HOW THE BRAIN WORKS IN THE CLASSROOM
}

\author{
Mojtaba Soltanlou ${ }^{1,2,3,4^{*}}$ and Christina Artemenko ${ }^{1,2}$ \\ ${ }^{1}$ Department of Psychology, University of Tübingen, Tübingen, Germany \\ ${ }^{2}$ LEAD Graduate School \& Research Network, University of Tübingen, Tübingen, Germany \\ ${ }^{3}$ Brain and Mind Institute, University of Western Ontario, London, ON, Canada \\ ${ }^{4}$ Department of Psychology, University of Western Ontario, London, ON, Canada
}

YOUNG REVIEWERS: ISTITUTO

EUROPEO LEOPARDI

AGES: 11-12
Did you know that we can study the brain in the classroom? Many people think that studying the brain is only possible in complex laboratories with huge, complicated devices. Functional near-infrared spectroscopy (fNIRS) is a new technique that uses light to monitor how active the brain is. fNIRS has several advantages that make it particularly good for observing the brains of babies and children. Also, it is one of the best techniques to study brain function in daily life and real situations, such as in the classroom or during a conversation. However, like all other brain measurement techniques, it cannot be used for everything, meaning that it has limitations. In this article, we discuss how fNIRS works and how it can be used, its advantages, and its limitations. We conclude that, when used in the field of Educational Neuroscience, fNIRS can help scientists to understand how children learn. 
Figure 1

(A) fNIRS uses light to look at brain function. (B) Sources (red) and detectors (blue) of the light in fNIRS. The light passing through the brain is shown as yellow banana shapes. (C) An fNIRS cap on the head of a baby

\section{FUNCTIONAL}

NEAR-INFRARED SPECTROSCOPY

(FNIRS)

A new technique that can help scientists easily monitor how the brain works by using a special type of light called

near-infrared light.

NEAR-INFRARED

\section{LIGHT}

A special type of light that can go through skin, bone, and brain and be used to measure what is going on in the brain.

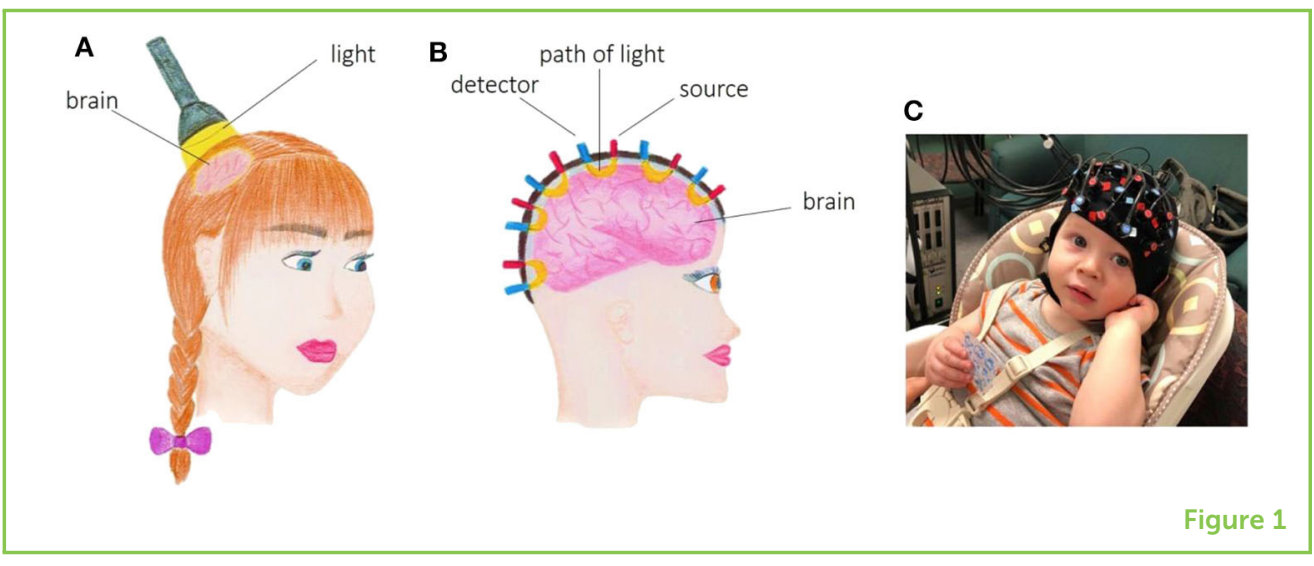

\section{WHAT IS FUNCTIONAL NEAR-INFRARED SPECTROSCOPY (FNIRS)?}

Functional near-infrared spectroscopy (fNIRS) is a new technique that helps researchers easily monitor how the brain works. fNIRS uses a special type of light called near-infrared light (Figure 1A). Near-infrared light is special because it can go through skin, bone, and brain. The light is sent into the brain from a light source (red in Figure 1B) and then received by a detector when it comes back out (blue in Figure 1B). The difference in the amount of light sent into the brain and the amount of light received shows how active the brain is. But why there is a difference between the sent and received light? Is a part of the light lost on its way through the brain?

To answer these questions, we need to understand how the brain works. The brain works by using oxygen. Oxygen is brought to the brain by the blood. When the brain is active, there is more blood flow and that means there is more oxygen in the brain. Blood absorbs near-infrared light, so when we send this light into the active brain, less light comes back, because some was absorbed by the blood. So: the more light absorbed, the less light we get back out, and the more active the brain is.

\section{WHAT ARE THE ADVANTAGES, USES, AND LIMITATIONS OF FNIRS?}

fNIRS has several advantages including:

- it allows testing while participants are sitting or standing

- it is easy to carry around and can be used almost anywhere

- it is easy and only takes minutes to set up

- it is cheap to use

- it measures brain function several times per second

- it neither hurts nor makes noise

- it can be used together with other brain measurement techniques

- it tolerates body movements, like talking, writing, or walking. 
Figure 2

fNIRS can be used in many different situations in daily life, such as during eating, conversation, dancing, and playing music. It can be used to see what happens in the brains of a mother and her baby when they communicate with each other.

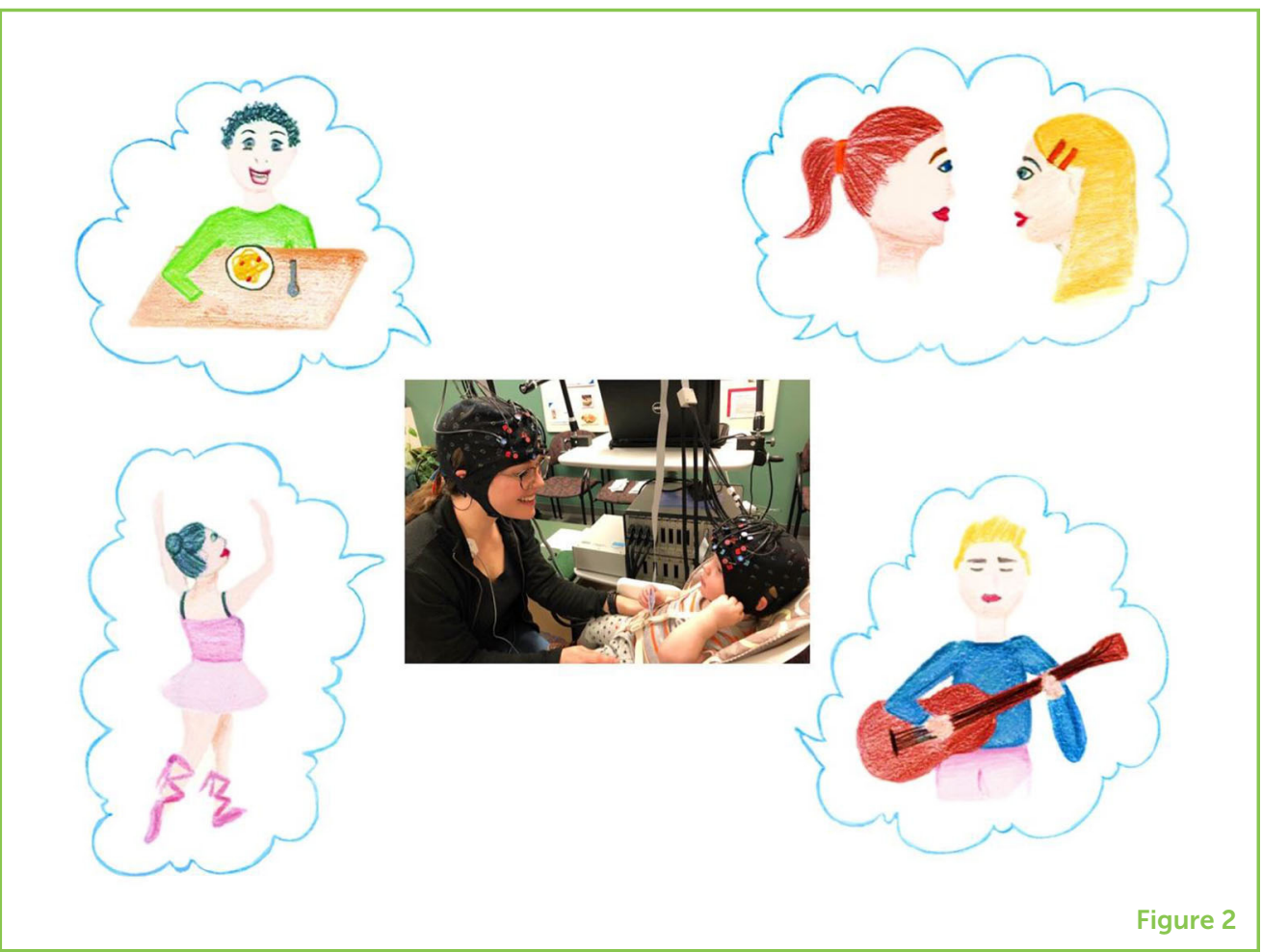

These advantages make fNIRS good for several uses (Figure 2). For one, we can study the brain in a natural environment and daily-life situations rather than only in laboratories. This is possible because some fNIRS devices are small enough that they can be carried to wherever the study will be performed. Furthermore, during measurements, the participants do not have to be lying down. They can sit behind a desk and do some homework or work on the computer. fNIRS can be used to study more complicated mental tasks than some other brain measurement techniques can and not just multiple choice tasks. Also, fNIRS is pretty comfortable for the participant. This means that we can study the brain even in babies and children (Figure 1C). It is usually difficult to study the brain in these young populations because they move a lot, making other brain measurement techniques impossible to use. Additionally, it is possible to measure brain function for a long time (up to $1 \mathrm{~h}$ ), and in many participants at the same time. Most of these advantages make fNIRS a unique technique for studying the brain in situations and people that are usually difficult or sometimes impossible to access with other techniques.

These advantages and uses, however, come with a price. We need to be aware of the limitations of fNIRS. First, fNIRS measures around $3 \mathrm{~cm}$ of the brain at one time. When we are talking about the brain this is a big area, because different parts within the brain are so small. So, an fNIRS measurement might include parts of the brain with different functions and therefore will not be as precise as measurements done with some other techniques [1]. Additionally, fNIRS can only measure the activation of areas around $1.5-2 \mathrm{~cm}$ deep into the brain. Therefore, 


\section{Figure 3}

While a child solves a mathematics problem, her brain function is recorded by fNIRS.

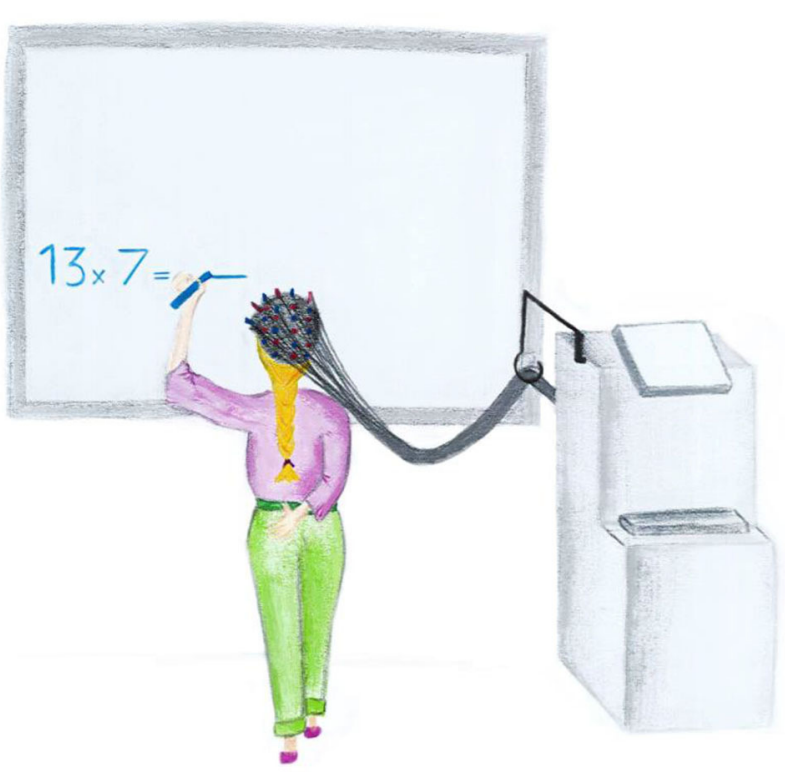

Figure 3

it is not good for measuring functions that are located deep inside the brain. Next, fNIRS provides information only about functions and not structures [1]. That means we can understand how the brain works, but not what the brain looks like. Furthermore, because it measures the amount of blood, fNIRS is sensitive to the heartbeat, blood pressure, and veins in the skin. So, some non-brain changes might be mixed up with brain function measurements. Finally, because fNIRS is a new technique, not everyone uses the same method of data analysis. Data analysis is a procedure to combine and transform the collected brain data of different people to show it in a way that everybody understands. In summary, when scientists want to measure brain function with $\mathrm{fNIRS}$, they need to be aware of both its advantages and its limitations.

\section{HOW IS FNIRS PERFORMED AND HOW IS ITS DATA USED?}

Depending on the study and research question, participants can be measured individually or in groups. To perform fNIRS, we need to follow a few steps. First, we measure the head of the participant to find some important points, like the center of the head. By using these points, we can estimate which part of the brain is measured by each sensor. Second, we attach the light sources and detectors on the head, using an elastic cap. Third, we ask our participant to perform a task while his/her brain function is measured by fNIRS (Figure 3). The task can be anything, for example, mathematical problems. Fourth, after the participant has finished the task, we turn off the fNIRS machine and take the cap off the participant's head, and the experiment is finished. 
We usually repeat the same experiment with many participants (about 40 children). Then we can analyze the data of all participants. But what does that mean? Let us imagine that our research question is "Which parts of the brain are active during calculation?" To answer this question, we measure brain function in two situations: when participants are solving mathematical problems and when they are just resting. Using computer software, we can read and combine the data of all participants. We then calculate the brain function levels during calculation and rest for all participants. Then we compare these brain function levels. We observe a huge difference between brain function levels during calculation and rest in some parts of the brain, but not in others. Therefore, we can conclude that only those parts of the brain that showed a huge difference between calculation and rest are important for calculation.

EDUCATIONAL NEUROSCIENCE

A field of brain study that aims to make education better in schools.

\section{CONCLUSION}

fNIRS is a technique that allows the measurement of brain function, even in special groups, such as babies and children [2], and in real-life situations, such as the classroom [3]. These capabilities make fNIRS very good for Educational Neuroscience research [4]. Educational Neuroscience uses techniques, such as fNIRS to study the brain and uses the results of brain studies to make education better in schools. While most of the commonly used brain techniques are great for studies in adults, they have several limitations when used in children, which is why we still do not know much about how the brain changes as we grow from babies to adults. Fortunately, fNIRS allows us to monitor brain changes and learning in children $[5,6]$. We believe that using fNIRS in Educational Neuroscience will eventually help us to understand how children learn to read, write and calculate.

\section{ACKNOWLEDGMENTS}

We would like to thank Bahar Rad, a 16-year-old artist, for illustration of the figures, Merle Bode for figure editing and Zoë Kirste for language proofreading. We also thank Megan and Warren for their permission to use their photos of participating in an fNIRS study. We would also like to thank those who assisted in the translation of the articles in this Collection to make them more accessible to kids outside English-speaking countries, and for the Jacobs Foundation for providing the funds necessary to translate the articles. For this article, we would especially like to thank Nienke van Atteveldt and Sabine Peters for the Dutch translation.

\section{REFERENCES}

1. Hoyos, P., Kim, N., and Kastner, S. 2019. How is magnetic resonance imaging used to learn about the brain? Front. Young Minds 7:86. doi: 10.3389/frym. 2019.00086 
2. Edwards, L. A., Wagner, J. B., Simon, C. E., and Hyde, D. C. 2016. Functional brain organization for number processing in pre-verbal infants. Dev. Sci. 19:757-69. doi: $10.1111 /$ desc.12333

3. Obersteiner, A., Dresler, T., Reiss, K., Vogel, A. C. M., Pekrun, R., and Fallgatter, A. J. 2010. Bringing brain imaging to the school to assess arithmetic problem solving: chances and limitations in combining educational and neuroscientific research. ZDM 42:541-54. doi: 10.1007/s11858-010-0256-7

4. Soltanlou, M., Sitnikova, M. A., Nuerk, H.-C., and Dresler, T. 2018. Applications of functional near-Infrared spectroscopy (fNIRS) in studying cognitive development: the case of mathematics and language. Front. Psychol. 9:277. doi: 10.3389/fpsyg.2018.00277

5. Artemenko, C., Soltanlou, M., Ehlis, A.-C., Nuerk, H.-C., and Dresler, T. 2018. The neural correlates of mental arithmetic in adolescents: a longitudinal fNIRS study. Behav. Brain Funct. 14:5. doi: 10.1186/s12993-018-0137-8

6. Soltanlou, M., Artemenko, C., Ehlis, A.-C., Huber, S., Fallgatter, A. J., Dresler, T., et al. 2018. Reduction but no shift in brain activation after arithmetic learning in children: a simultaneous fNIRS-EEG study. Sci. Rep. 8:1707. doi: 10.1038/ s41598-018-20007-x

SUBMITTED: 25 October 2019; ACCEPTED: 04 June 2020; PUBLISHED ONLINE: 10 July 2020.

\section{EDITED BY: Stephan E. Vogel, University of Graz, Austria}

CITATION: Soltanlou M and Artemenko C (2020) Using Light to Understand How the Brain Works in the Classroom. Front. Young Minds 8:88. doi: 10.3389/frym. 2020.00088

CONFLICT OF INTEREST: The authors declare that the research was conducted in the absence of any commercial or financial relationships that could be construed as a potential conflict of interest.

COPYRIGHT @ 2020 Soltanlou and Artemenko. This is an open-access article distributed under the terms of the Creative Commons Attribution License (CC BY). The use, distribution or reproduction in other forums is permitted, provided the original author(s) and the copyright owner(s) are credited and that the original publication in this journal is cited, in accordance with accepted academic practice. No use, distribution or reproduction is permitted which does not comply with these terms.

\section{YOUNG REVIEWERS}

\section{ISTITUTO EUROPEO LEOPARDI, AGES: 11-12}

We are a group of students from the Istituto Europeo Leopardi and we are in 1st year of middle school. Our names are Lucrezia, Sofia, Benedetta, Eleonora, Francesco, Matteo, Marco, Emma, Greta e Lidia. We live in Milan (Italy) and we are 11-12 years old. We are a funny, nice, creative class, and we like Science and Sport. Good Bye from the 1 st $A$ ! 

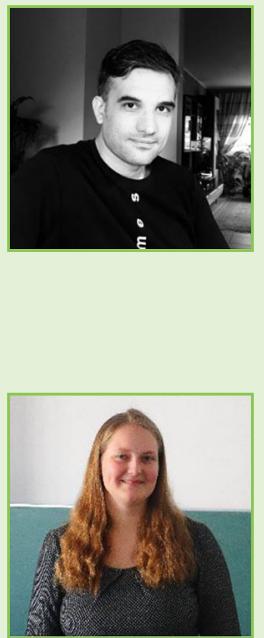

\section{AUTHORS}

\section{MOJTABA SOLTANLOU}

I am a researcher at the University of Western Ontario in Canada. Before going into research, I used to work as a therapist, helping children who had various disorders. In my research, I would like to understand what happens in the brain when a child learns something like mathematics, and why some children have difficulties in learning. In my free time, I like doing sport, playing the Tar, and reading about history. *mojtaba.soltanlou@gmail.com

\section{CHRISTINA ARTEMENKO}

I am a researcher at the University of Tuebingen in Germany. My research is about math and calculation. I want to know what is going on in the brain when someone is calculating, and I use fNIRS to study the brain. I want to understand what makes calculation difficult and why some people have problems with math. Besides research, I also enjoy playing the flute, ballet, and volleyball. 